\title{
Rancang Bangun Body Fibercarbon dan Simulasi Aerodinamis dengan Ansys untuk Mobil Hemat Energi Kategori Prototype
}

\author{
${ }^{(1) *}$ Yusuf Eko Nurcahyo, (2) Pongky Lubas Wahyudi \\ ${ }^{(1,2)}$ Program Studi Teknologi Manufaktur, Universitas 17 Agustus 1945 Surabaya, Semolowaru 45 \\ Surabaya \\ *Email: yusufekonurcahyo@untag-sby.ac.id
}

Diterima: 28.09.2021 Disetujui: 20.10.2021 Diterbitkan: 25.10.2021

\begin{abstract}
Body is one of mandatory components for the main vehicle, which is a car because the face of the car is located on the body. Moreover, the car used for the body competition must not only be good visually but also have to look at its aerodynamics. In this study, discussing the aerodynamics of a prototype energy-efficient car body with carbon fiber material before it is produced and applied it must first be simulated aerodynamically on an aerodynamic simulation software. The vehicle to be simulated uses a 1:1 scale assuming the actual conditions. From the simulations carried out by the three body type models, the results are Model 1 with maximum Velocity of $64.0925 \mathrm{~m} / \mathrm{s}$ and a maximum pressure of 1663.09 Pa and a Drag coefficient of: 309.85976, Lift coefficient of: 125.52961, Drag force of : $189.7891 \mathrm{~N}$ and Lift force of: $76.886889 \mathrm{~N}$. Model 2 with a maximum Velocity of $58.14 \mathrm{~m} / \mathrm{s}$ and a maximum pressure of $1350.55 \mathrm{~Pa}$, Drag coefficient of : 399.09712, Lift coefficient of: 455.23564 , Drag force of : $244.44699 N$ and Lift force of: 278.83183 N. Model 3 with a maximum Velocity of $59.8387 \mathrm{~m} / \mathrm{s}$ and a maximum pressure of $1136.72 \mathrm{~Pa}$, Drag coefficient of : 610,89875, Lift coefficient of: 764,99562, Drag force of: 374,17548 N and Lift force of: 468,55982 N. Based on results analysis using ansys software, Model 1 was chosen because it has the smallest Drag Coefficient, Lift Coefficient, Drag Force and Lift Force.
\end{abstract}

Keywords: ANSYS R19.0, CFD, Aerodynamics, Drag Coefficient, Lift Coefficient

\begin{abstract}
ABSTRAK
Body merupakan salah satu komponen wajib bagi kendaraan utamanya adalah mobil karena wajah dari mobil terletak pada body nya. Apalagi mobil yang dipergunakan untuk kompetisi body tidak hanya harus bagus dari visual tetapi juga harus dilihat aerodinamisnya. Dalam penelitian kali ini membahas tentang aerodinamis sebuah body kendaraan mobil hemat energi prototipe dengan bahan fibercarbon sebelum diproduksi dan diaplikasikan terlebih dahulu harus disimulasikan aerodinamis pada sebuah software simulasi aerodinamis pada penelitian ini digunakan bantuan software ANSYS R19.0 dengan metode Computional Fluid Dynamics (CFD). Rancangan Body yang dimulasikan sesuai dengan keadaan sebenarnya. Dari simulasi yang dilakukan ketiga model tipe body didapatkan hasil Model 1 dengan Velocity sebesar maksimal 64,0925 m/s dan pressure maksimal sebesar 1663,09 Pa serta koefisien Drag sebesar : 309,85976, koefisien Lift sebesar: 125,52961, Drag force sebesar : 189,7891 $\mathrm{N}$ dan Lift force sebesar: 76,886889 N. Model 2 dengan Velocity sebesar maksimal 58,14 m/s dan pressure maksimal sebesar 1350,55 Pa koefisien Drag sebesar : 399,09712, koefisien Lift sebesar: 455,23564, Drag force sebesar : 244,44699N dan Lift force sebesar: 278,83183 N. Model 3 dengan Velocity sebesar maksimal 59,8387 m/s dan pressure maksimal sebesar 1136,72 Pa koefisien Drag sebesar : 610,89875, koefisien Lift sebesar: 764,99562, Drag force sebesar : 374,17548 N dan Lift force sebesar: 468,55982 N. Berdasarkan hasil Analisa dengan software ansys dipilih Model 1 karena mempunyai koefisien Drag, koefisien Lift, Drag force dan Lift force terkecil.
\end{abstract}

Kata Kunci: ANSYS R19.0, CFD, Aerodinamis, koefisien Drag, koefisien Lift

\section{Pendahuluan}

Jaman yang era cepat secara langsung menuntut mobilitas masyarakat yang harus cepat sehingga mempengaruhi perkembangan industri kendaraan bermotor baik berupa mobil ataupun sepeda motor ini ditunjukkan oleh data dari BPS yang menunjukkan pada tahun 2017 
jumlah kendaraan bermotor adalah 118922708 meningkat menjadi 126508776 pada tahun 2018 dan meningkat lagi 133617012 unit pada tahun 2019 (Badan Pusat Statistik, 2017).

Dengan makin bertambahnya jumlah kendaraan bermotor akan mengakibatkan berkurangnya bahkan bisa habis bahan bakar Fosil dan menyebabkan menipisnya ozon yang bisa memicu pemanasan global. Solusi terbaik dalam mengatasi permasalahan tersebut salah satunya melakukan penelitian kendaraan dengan bahan bakar alternatif sebagai solusi kendaraan untuk masa depan dengan desain khusus.

Peneliti berupaya melakukan penelitian pembuatan body mobil KMHE pada kategori prototype motor listrik. Merancang body kendaraan mobil hemat energi harus berdasar pada regulasi untuk Kompetisi Mobil Hemat Energi (KMHE) kategori prototype. Kompetisi KMHE memiliki tujuan utama yaitu menciptakan kendaraan yang hemat bahan bakar. Bentuk body kendaraan sangat mempengaruhi performa sebuah kendaraan utamanya yang berkaitan dengan aerodinamika.

Aerodinamika pada penelitian ini dibagi menjadi 2 yaitu Drag force dan Lift force. Drag force ini merupakan gaya yang mempunyai sifat penghambat arah laju kendaraan sedangkan Lift merupakan gaya yang memiliki sifat pengangkat kendaraan. Gaya tersebut dipengaruhi oleh bentuk body, dimensi dan kecepatan suatu kendaraan.

Body Aerodinamis pada sebuah kendaraan dapat mempengaruhi efisiensi bahan bakar dan memeinimalkan suatu gaya yang terjadi pada saat kendaraan sejang melaju. Berbagai cara agar dapat merancang body aerodinamis suatu kendaraan salah satunya yang dapat dilakukan adalah dengan menggunakan metode CFD. Metode CFD sangat direkomendasikan dikarenakan hasil akurat dan hemat biaya karena menggunakan bantuan software.

Penelitian ini bertujuan membahas tentang aerodinamis sebuah body kendaraan mobil hemat energi prototipe dengan bahan fibercarbon sebelum diproduksi dan diaplikasikan terlebih dahulu harus disimulasikan aerodinamis pada sebuah software simulasi aerodinamis. Pengujian yang dilakukan adalah simulasi Drag force, Lift force dan side force. Pengujian ini menggunakan salah satu perangkat lunak desain yaitu ANSYS R19.0.

\section{Bahan dan Metode}

\section{Sket Body Mobil Hemat Energi}

Penelitian ini membuat terlebih dahulu gambar sketsa sasis kendaraan. Desain dilakukan dengan melakukan gambar manual dengan memperhatikan aturan dimensi yang ada pada panduan KMHE.

\section{Desain Body Mobil Hemat Energi}

Pembuatan gambar Body 2D serta 3D bertujuan untuk memberikan suatu penjelasan detail pada desain yang akan dipilih untuk diproduksi. Dimana desain body mobil ini menggunakan software Solidwork dengan material fiber carbon seperti pada Tabel 1 sebagai berikut:

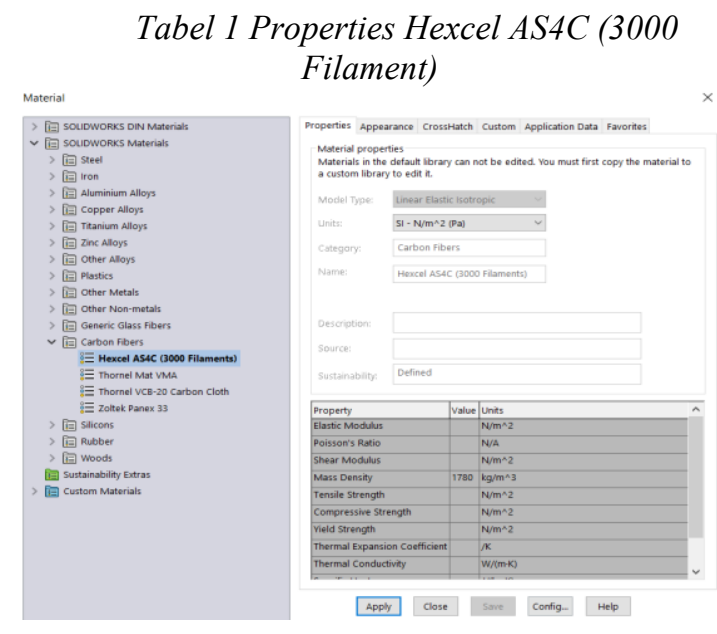

\section{Simulasi Body Mobil Hemat Energi}

Simulasi body bertujuan memilih model body yang paling aerodinamis dengan mengetahui besar distribusi Koefisien Drag, Koefisien Lift, Drag force dan Lift force. Simulasi desain body menggunakan Software ANSYS 19.

\section{Analisis Simulasi Sasis}

Simulasi aerodinamis pada desain body bertujuan untuk mengetahui besar distribusi Koefisien Drag, Koefisien Lift, Drag force dan Lift force. Simulasi aerodinamis pada desain body menggunakan Software ANSYS 19 agar lebih cepat dan efisien untuk mencari dan menentukan arah tegangan pada sebuah objek. Kemudian dipilih yang terkecil karena semakin kecil Koefisien Drag, Koefisien Lift, Drag 
force dan Lift force maka semakin aerodinamis body tersebut.

\section{Hasil dan Pembahasan}

\section{Desain Body Mobil Hemat Energi}

Dalam penelitian kali ini dibuat tiga model desain yang nantinya akan disimulasikan dan dianalisa kemudian berdasarkan hasil Analisa akan dipilih body yang paling aerodinamis untuk direalisasikan.

\section{Desain Model 1}

Pada Desain Model 1 yang telah disesuaikan dengan peraturan dalam Panduan Kompetisi Mobil Hemat Energi diperoleh dimensi sebagai berikut :

$$
\begin{array}{ll}
\text { - Panjang } & : 2650,13 \mathrm{~mm} \\
\text { - Lebar } & : 918,99 \mathrm{~mm} \\
\text { - Tinggi } & : 768,39 \mathrm{~mm}
\end{array}
$$

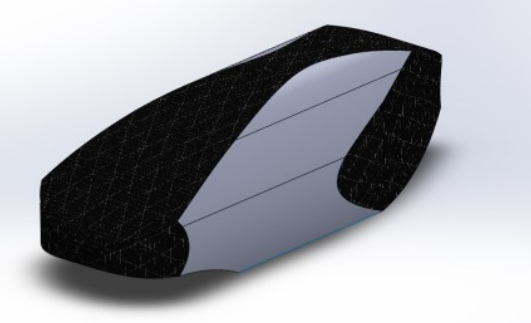

Gambar 1 Desain 3D Model 1

\section{Desain Model 2}

Pada Desain Model 2 yang telah disesuaikan dengan peraturan dalam Panduan Kompetisi Mobil Hemat Energi diperoleh dimensi sebagai berikut :

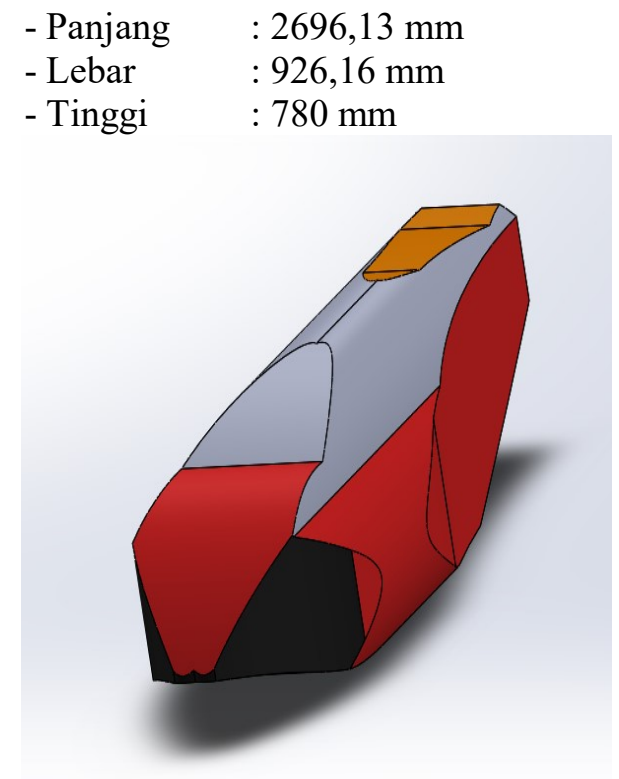

Gambar 2 Desain 3D Model 2

\section{Desain Model 3}

Pada Desain Model 3 yang telah disesuaikan dengan peraturan dalam Panduan Kompetisi Mobil Hemat Energi diperoleh dimensi sebagai berikut :

$$
\begin{array}{ll}
\text { - Panjang } & : 2696,13 \mathrm{~mm} \\
\text { - Lebar } & : 924,30 \mathrm{~mm} \\
\text { - Tinggi } & : 780 \mathrm{~mm}
\end{array}
$$

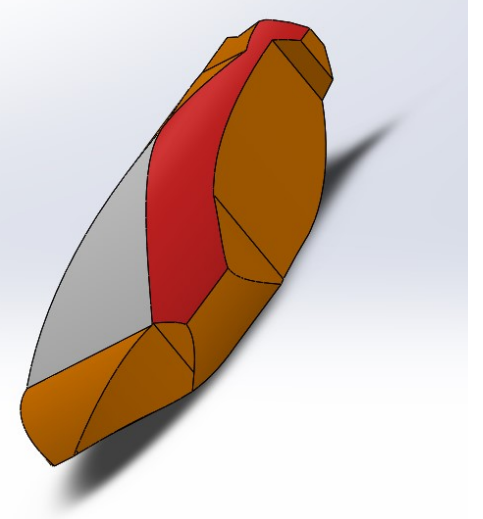

Gambar 3 Desain 3D Model 3

\section{Simulasi}

\section{Simulasi Model 1}

Pengujian Model 1 dengan menggunakan ANSYS R19.0 dengan metode CFD atau Computational Fluid Dynamics merupakan suatu Analisa yang dipergunakan untuk menghitung aliran udara dan tegangan gaya pada suatu body yang sedang bergerak dengan kecepatan tertentu dalam ANSYS R19.0 metode ini disebut dengan fluent.

\section{Velocity}

Velocity merupakan kecepatan udara yang biasanya digunakan dalam pengujian fluent aerodinamis untuk mengetahui seberapa besar kecepatan udara yang mampu menghambat suatu body.

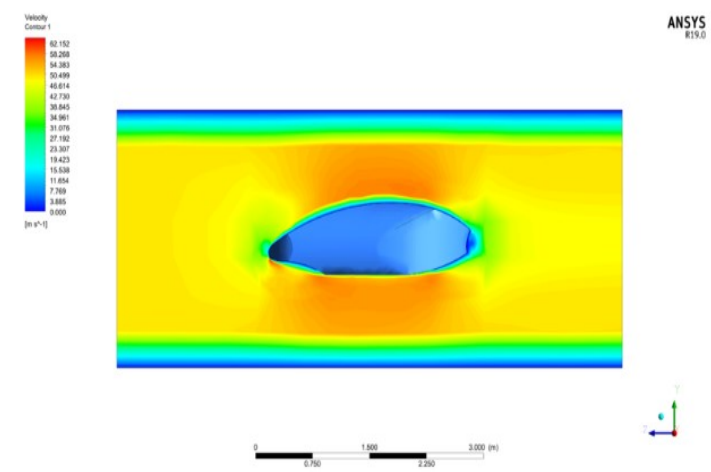

Gambar 4 Velocity Contour Model 1 


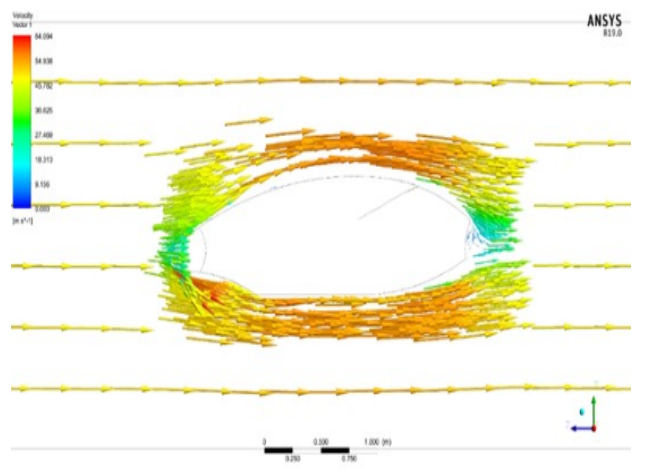

Gambar 5 Velocity Vektor Model 1

Dari gambar 4 dan 5 dilihat bahwa kecepatan udara maksimal yang dihasilkan adalah $64,0925 \mathrm{~m} / \mathrm{s}$ yang ditunjukkan oleh warna merah dan panah menunjukkan arah dari kecepatan udara yang menunjukkan daerah yang memiliki hambatan yang paling besar.

\section{Presure}

Preseure merupakan tekanan yang diterima oleh body semakin kecil Preseure yang didaptkan semakin kecil gaya yang dikeluarkan.
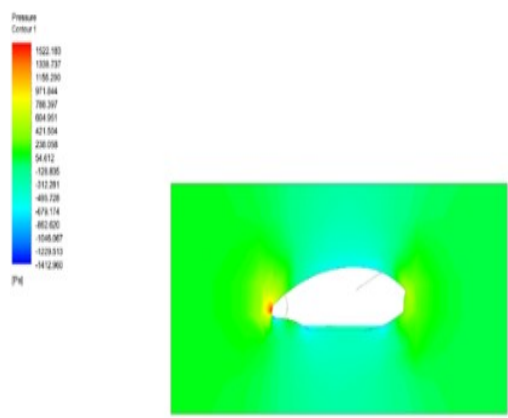

ANSYS

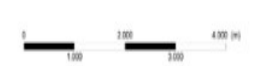

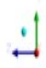

\section{Gambar 6 Presure Contour Model 1}

Apabila suatu udara mengalir pada body akan terjadi tekanan yang dihasilkan atau tekanan yang dapat dilewati oleh body pada gambar 3.6 dapat dilihat pressure maksimal yang dapat dilewati oleh body Model 1 adalah sebesar $1663,09 \mathrm{~Pa}$ dan terjadi pada ujung moncong body yang ditunjukkan warna merah.

\section{Koefisien Drag dan Koefisien Lift}

Drag merupakan suatu gaya penghambat dari pergerakan sebuah benda padat yang bergerak pada fluida baik cair ataupun gas(udara) yang mempunyai arah sejajar tapi berlawanan arah dengan sumbu kecepatan benda tersebut. Sedangkan Koefisien Drag merupakan bilangan besar dan kecilnya suatu tahanan fluida terhadap suatu benda.

Lift adalah gaya angkat yang dapat mengangkat benda keatas ini bisa terjadi akibat tekanan bawah lebih besar dari tekanan atas benda. Koefisien Lift merupakan parameter yang menunjukkan besar kecilnya gaya Lift yang bekerja pada suatu benda.

\begin{tabular}{|c|c|c|c|c|}
\hline \multicolumn{4}{|c|}{ Outine of All Parameters } & $\sqrt{4 x}$ \\
\hline & A & B & c & D \\
\hline 1 & ID & Parameter Name & Value & Unit \\
\hline 2 & 曰 Input Parameters & & & \\
\hline$*$ & le New input parameter & New name & New expression & \\
\hline 4 & 曰 Output Parameters & & & \\
\hline 5 & $\square \bigcirc$ Fluid Flow (Fluent) (A1) & & & \\
\hline 6 & ped P1 & drag-coifisien-op & $-309,86$ & \\
\hline 7 & pet P2 & lift-coifsien-op & $-125,53$ & \\
\hline 8 & pat P3 & drag-force-op & $-189,79$ & $\mathrm{~N}$ \\
\hline 9 & pal P5 & force-op & $-42,763$ & $\mathrm{~N}$ \\
\hline 10 & pal P6 & lift-force-op & $-76,887$ & N \\
\hline$*$ & ped New output parameter & & New expression & \\
\hline 12 & Charts & & & \\
\hline
\end{tabular}

Gambar 7 Outline All Parameter Model 1

\section{Simulasi Model 2}

\section{Velocity}

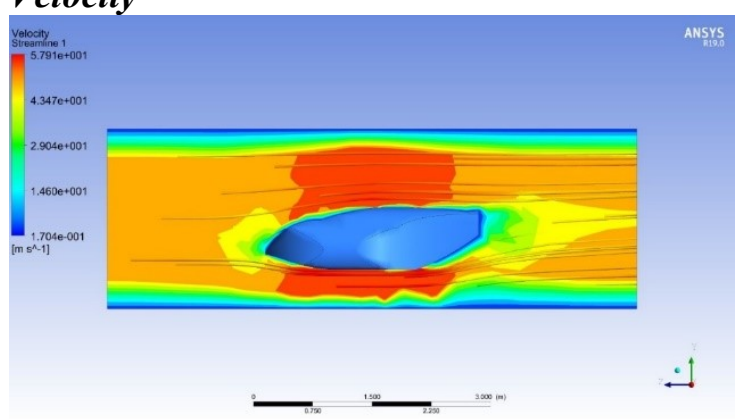

Gambar 8 Velocity Contour Streamine Model 2

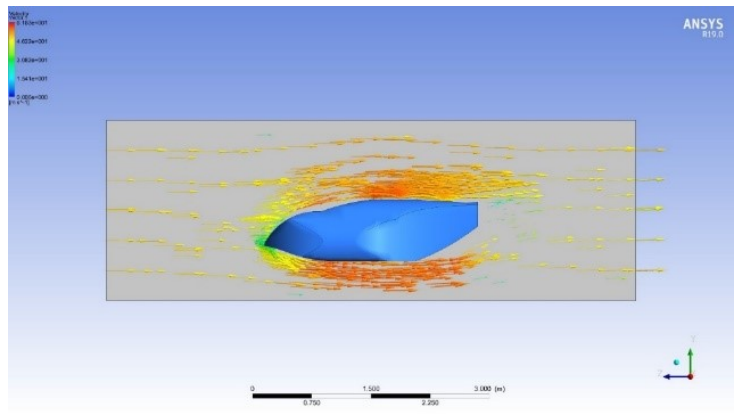

Gambar 9 Velocity Vektor Model 2

Dari gambar diatas menunjukkan bahwa kecepatan makasimal udara sebesar 58,14 m/s yang ditunjukkan oleh warna merah dan panah menunjukkan arah dari kecepatan udara. 


\section{Pressure}

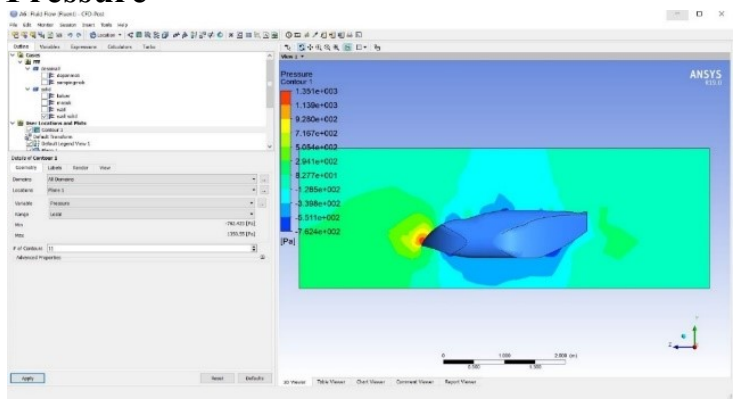

Gambar.10 Presure Contour Model 2

Pressure maksimal yang dapat dilewati oleh body Model 1 adalah sebesar 1350,55 Pa dan terjadi pada ujung moncong body yang ditunjukkan warna merah

\section{Koefisien Drag dan Koefisien Lift}

Model 2 didapatkan hasil Koefisien Drag sebesar : 399,09712, Drag force sebesar : 244,44699 N, koefisien Lift sebesar: 455,23564 dan Lift force sebesar: $278,83 \mathrm{~N}$

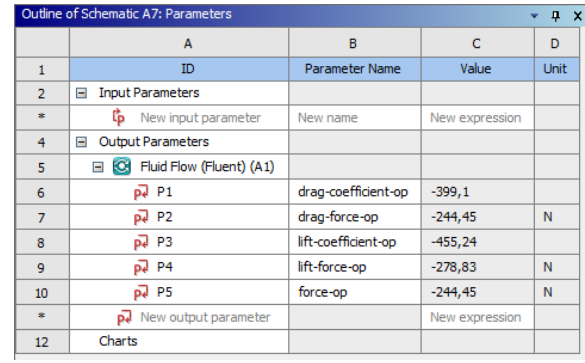

Gambar 11 Outline All Parameter Model 2

\section{Simulasi Model 3 \\ Velocity}

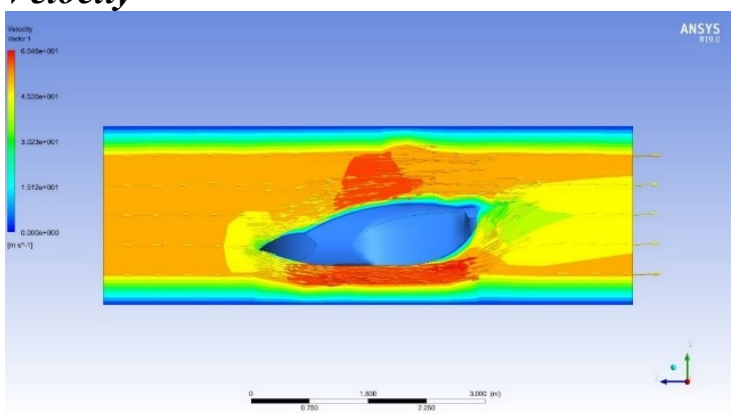

Gambar 12 Velocity Contour Streamine Model 3

Velocity Contour Streamine maksimal sebesar $59,8387 \mathrm{~m} / \mathrm{s}$ yang ditunjukkan oleh warna merah

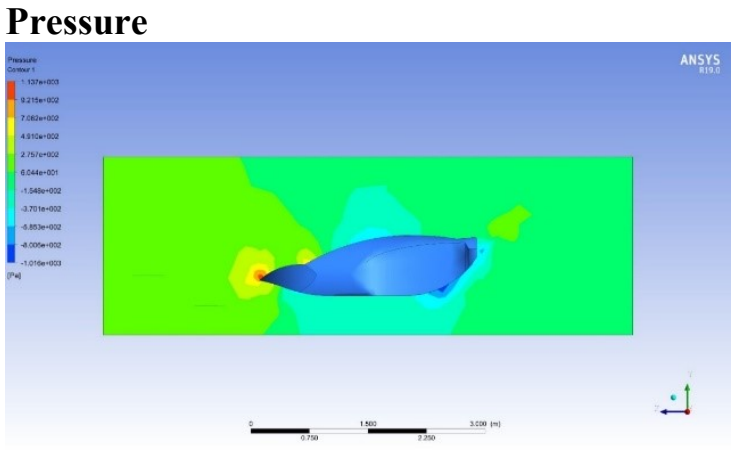

Gambar 13 Presure Contour Model 3

Pressure maksimal yang dapat dilewati oleh body Model 3 adalah sebesar 1136,72 $\mathrm{Pa}$ dan terjadi pada ujung moncong body yang ditunjukkan warna merah

\section{Koefisien Drag dan Koefisien Lift}

Hasil dari pengujian simulasi dengan Ansys R19.0 pada Model 3 didapatkan hasil Koefisien Drag sebesar : 610,89875 dan Drag force sebesar : 374,17548 serta koefisien Lift sebesar: 764,99562 dan Lift force sebesar: 374,1754N.

\begin{tabular}{|c|c|c|c|c|}
\hline \multicolumn{4}{|c|}{ Outline of Schematic A7: Parameters } & $4 x$ \\
\hline & A & B & c & D \\
\hline 1 & ID & Parameter Name & Value & Unit \\
\hline 2 & 日 Input Parameters & & & \\
\hline$*$ & lp New input parameter & New name & New expression & \\
\hline 4 & $\boxminus$ Output Parameters & & & \\
\hline 5 & $\square$ Fluid Flow (Fluent) (A1) & & & \\
\hline 6 & PA P2 & lift-force-op & $-468,69$ & $\mathrm{~N}$ \\
\hline 7 & Pa P3 & force-op & $-374,27$ & $\mathrm{~N}$ \\
\hline 8 & ped P4 & drag_coeeficient-op & $-611,05$ & \\
\hline 9 & Pa P5 & drag-force-op & $-374,27$ & $\mathrm{~N}$ \\
\hline 10 & pat P6 & lif-coeeficient-op & $-765,21$ & \\
\hline$*$ & p] New output parameter & & New expression & \\
\hline 12 & Charts & & & \\
\hline
\end{tabular}

Gambar 14 Outline All Parameter Model 3

\section{Analisa}

Tujuan dari analisa dalam penelitian ini adalah untuk mencari desain Terbaik hasil Simulasi CFD Fluent dengan ANSYS R19.0. Kriteria desain terbaik atau yang paling aerodinamis adalah Velocity dan Pressure Terbesar serta Koefisien Drag, Koefisien Lift, Drag force, Lift force terkecil. Berikut adalah hasil simulasi bisa dilihat pada tabel berikut : 
Tabel 1 Hasil Simulasi

\begin{tabular}{lcccccc}
\hline \multirow{2}{*}{ Body } & \multicolumn{5}{c}{ Hasil Simulasi ANSYS R19.0 } \\
\cline { 2 - 7 } & Velocity & Pressure & Koefisien Drag & Koefisien Lift & Drag force & Lift force \\
\hline Model 1 & $64,0925 \mathrm{~m} / \mathrm{s}$ & $1663,09 \mathrm{~Pa}$ & 309,85976 & 125,52961 & $189,7891 \mathrm{~N}$ & $76,886889 \mathrm{~N}$ \\
& & & & & & \\
\hline Model 2 & $58,14 \mathrm{~m} / \mathrm{s}$ & $1350,55 \mathrm{~Pa}$ & 399,09712 & 455,23564 & $244,44699 \mathrm{~N}$ & $278,83183 \mathrm{~N}$ \\
\hline Model 3 & $59,8387 \mathrm{~m} / \mathrm{s}$ & $1136,72 \mathrm{~Pa}$ & 610,89875 & 764,99562 & $374,17548 \mathrm{~N}$ & $468,55982 \mathrm{~N}$
\end{tabular}

Berdasarkan Tabel di atas dapat dilihat bahwa dari segi persyaratan Desain Body Model 1 yang terbaik dimana mempunyai Velocity dan Pressure Terbesar serta Koefisien Drag, Koefisien Lift, Drag force, Lift force terkecil. Maka dipilih Model 1 untuk dilakukan produksi.

\section{Kesimpulan}

Kesimpulan dari hasil perancangan dan hasil Analisa dengan bantuan software dipilih Model 1 karena mempunyai Koefisien Drag, Koefisien Lift, Drag force dan Lift force terkecil dengan hasil simulasi :

1. Velocity sebesar maksimal $64,0925 \mathrm{~m} / \mathrm{s}$

2. Pressure maksimal sebesar $1663,09 \mathrm{~Pa}$

3. Koefisien Drag sebesar : 309,85976

4. Koefisien Lift sebesar: 125,52961

5. Drag force sebesar : $189,7891 \mathrm{~N}$

6. Lift force sebesar: $76,886889 \mathrm{~N}$.

\section{Ucapan Terima Kasih}

Penulis sangat berterimakasih kepada Lembaga Penelitian dan Pengabdian Masyarakat Untag Surabaya yang telah bersedia membiayai seluruh penelitian ini.

\section{Daftar Pustaka}

Anderson, John D., Jr., 1986. Fundamental of aerodynamic, Mc Graw-Hill, New York.

Azwir, Hail. 2014. “Analisa Computional Fluid Dynamic body kendaraan Mataram Proto dengan prangkat lunak ansys fluent 14". Tugas Akhir Tenik Mesin, IST AKPRIND, Yogyakarta

Badan Pusat Statistik. (2017). Badan Pusat Statistik (pp. 335-358). https://doi.org/10.1055/s-2008-1040325
Dieter L. Goerge., \& Schmidt C. Linda., 2009, Engineering Design, Fourth Edition, Published by McGraw-Hill Companies, New York.

Gerhart, Philip M, Gross, Richard J., \& Hochstein, John I., 1992, Fundamentals of Fluid mechanics, 2nd ed, AddisonWesley Publishing Company., New York.

Hall, Nancy. 2015. The Lift Coefficient, termuada dalam web:

https://www.grc.nasa.gov/www/k-

12/airplane/Liftco.html, diakses 9 Juli $\underline{2021 .}$.

Hamidi, Abdullah., 2011, Analisa Aerodinamika Pada Permukaan Urban Concept Car SEM UI "Kalibaya" dengan CFD, Tugas Akhir Tenik Mesin, Universitas Indonesia, Depok.

Hirt, Tony. 2016, Modeling Turbulence Viscosity, termuat dalam https://www.cfd online.com/Wiki/Standard $k$ epsilon model\#Modeling\%20 turbulent viscosity, diakses 9 Juli 2021.

Hucho, Wofl-Heinrich., 1998, Aerodynamic of road vehicles, 4th ed, SAE international, London.

Huda, Nurul. 2016. Analisa Aerodinamika Pada Mobil Bayu Surya Menggunakan CFD Pada Software Ansys 15.0. Tugas Akhir Teknik Mesin Universitas Muhammadiyah, Surakarta

Miliken, F, Wiliam \& Miliken, L, Douglas, 1995, Race Car Vehicle Dynamic, Volume 1, Society of Automotive Engineers, London.

Munson, Bruce R., Young, Donal F. \& Okiishi, Theodore H., 2003, Mekanika Fluida, 
Jilid 1, Edisi Ke 4, Alih Bahasa : Harinaldi \& Budiarso, Erlangga, Jakarta.

Norton L. Robert., 2013, Machine Design, Edition 5, Publisher Pearson Education, United States.

Sarif, Lukman,. 2013, Perancangan Aerodinamika Body Mobil Sport Berbasis Komputasi Dinamik Fulid Dengan Menggunakan Program Ansys 13.0, Tugas Akhir Teknik Mesin, IST Akprind, Yogyakarta

Siregar, Munawir Rosyadi dan Ambarita Himsar, 2012, Analisa Koefisien Drag Pada Mobil Hemat Energi "Mesin USU" Dengan Menggunakan Perangkat Lunak CFD, Jurnal e-Dinamis, Vol 3, No. 3 Desember 2012 